INTERNATIONAL JOURNALOF ORGANICEVOLUTION

P U B L I S H E D B Y

THE SOCIETY FOR THE STUDY OF EVOLUTION

\begin{tabular}{lll}
\hline Vol. 28 & June, 1974 & No. 2
\end{tabular}

\title{
THE EVOLUTION OF CLUTCH SIZE AND REPRODUCTIVE RATES IN PARASITIC CUCKOOS
}

\author{
Robert B. Payne \\ Museum of Zoology and Department of Zoology \\ University of Michigan, Ann Arbor, Michigan 48104
}

Received November 22, 1972

The ultimate causes of the evolution of reproductive rates in birds have been debated through the century. Many biologists have thought that high mortality rates in short-lived animals favor high reproductive rates to insure that parents replace themselves. In contrast, Lack (1954) and Williams (1966a) reasoned that the individuals producing more offspring will have their genes represented in increasing frequency in later generations regardless of mortality rate. Lack (1954) proposed that mean clutch size is precisely adjusted within each species by natural selection to match some certain maximum number of young in a brood that the parents can feed. Williams (1966a:164) "would interpret the increased mortality as an ecologically inevitable consequence of the increased fecundity." Individual fitness rather than "keeping the race from extinction" explains the evolution of reproductive rates.

Comparisons of the ecology of different populations of a single species have been made to determine the selective history of reproductive rates, especially of clutch size, but many of the results may be explained in more than one way (Lack, 1954; Skutch, 1967; Hussell, 1972). To understand the evolution of reproductive biology it would be desirable to compare not only variation within a species but also related species with divergent breeding ecologies. In several families of birds there are some species that rear their own young, and others, the brood parasites, that lay in the nests of unrelated species, the fosterers or hosts, which gather all the food for the young. Because brood parasites have evolved independently (Makatsch, 1955), the differences in clutch size between the parasites and their nesting relatives are unlikely to be phylogenetic sampling errors. Rather, natural selection will lead to differences in clutch size between the birds that provide food for their own young and those that do not. Because the main difference in the breeding of nesting and parasitic birds is the presence or absence of parental care of their own offspring, one might expect that the brood parasites would have larger clutches or some other measure of higher reproductive rates than their nesting relatives, if foodgathering and parental care determine reproductive rates. This hypothesis was tested on cuckoos (Cuculidae), a family in which brood parasitism has apparently evolved more than once and on a 


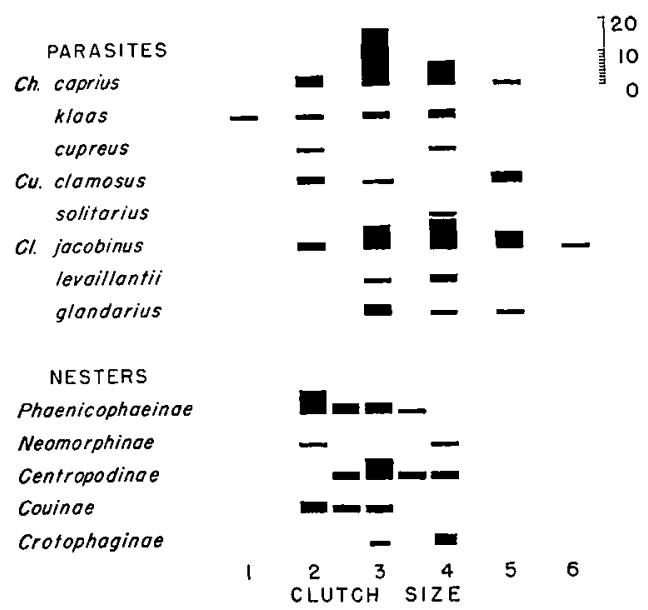

Fig. 1. Clutch size in parasitic cuckoos and nesting cuckoos. The mean clutch size for each species of nesting cuckoos (not individual clutches, as for the parasites) are shown. The vertical scale refers not to number of individual clutches of parasites, but to number of species of nesters. Data for nesting cuckoos are taken from many published sources, mainly Ali and Ripley (1969), Appert (1970), Bent (1940), McLachlan and Liversidge (1970), Mackworth-Praed and Grant (1957, 1970), and Wetmore (1968) and for the crotophagines from Beebe (1910) Sibley and Ahlquist (1973), and J. G. Strauch (pers. comm.). The clutches of 2.5 and 3.5 for some nesters are for species with clutch sizes in the literature of " 2 to 3 " or " 3 to 4."

world-wide basis and in which nearly half the species are parasites. Although the study was planned as a test of Lack's food/ parental care principle, and the results to some extent are those expected from it, some aspects of the evolution of reproductive rates in parasitic cuckoos may well be better explained by other, more general models.

\section{Materials AND Methods}

Parasitic cuckoos were collected in Africa in four breeding seasons from 1965 to 1972. Ovaries were fixed in the field and later examined in gross aspect and microscopically in serial sections. The laying histories of 103 individual females of nine species were determined by counting and aging postovulatory follicles. Use of standard morphological and histological techniques allows determination of the laying histories of birds during the two weeks prior to collection. In addition, the presence of large, yolky follicles in the ovaries indicates additional ovulations and layings, and, when the growth rates of the ovarian follicles can be determined, the larger yolky follicles can be predicted to ovulate within a few days (Payne, 1966, 1969). After laying rates for the two weeks were determined for each bird, seasonal reproductive rates were estimated from the two-week records and the duration of local breeding seasons. In all species sampled adequately the proportion of laying birds was high ( $50 \%$ or more) throughout the breeding season. The individual laying histories and local breeding seasons are described elsewhere (Payne, 1973).

\section{Ciutch Size}

Most parasitic cuckoos lay only one egg in any one nest of the foster species. Nevertheless, they ovulate and lay in more or less distinct series, or clutches, with eggs usually laid on alternate days and with four to eight days between each series. The data on clutch sizes are taken from illustrations (Payne, 1973) showing ovulations or probable ovulations separated by no more than $1 \frac{1 / 2}{2}$ days in a series. The more obviously incomplete "clutches" with only one or two post-ovulatory follicles in a series visible, where these were no more recent than 8 days, were disregarded (because slightly older ovulated follicles had degenerated beyond recognition), as were the incompleted series of approaching ovulations estimated entirely from yolky follicles where none had yet ovulated. The clutch sizes used here (Fig. 1) thus omit some of the smallest incomplete series illustrated. Individuals of a species varied the number of eggs in successive clutches; some Chrysococcyx caprius, for example, laid a clutch of two and then a clutch of four. Probably the variation of number of eggs in the series of an individual female accounts for much of the variation within a 
TABLE 1. Seasonal reproductive data in parasitic African cuckoos.

\begin{tabular}{lccccc}
\hline \hline \multicolumn{1}{c}{ Species } & $\begin{array}{c}\text { Breeding } \\
\text { season } \\
\text { (weeks) }\end{array}$ & $\begin{array}{c}\text { eggs } \\
\text { laid }\end{array}$ & $\begin{array}{c}\text { Egg } \\
\text { weight } \\
(\mathrm{g})^{2}\end{array}$ & $\begin{array}{c}\text { Estimated } \\
\text { total eggs } \\
\text { weight }(\mathrm{g})\end{array}$ & $\begin{array}{c}\text { Mean body } \\
\text { weight }(g))^{3} \\
\text { females }(N)^{3}\end{array}$ \\
\hline $\begin{array}{l}\text { Chrysococcyx caprius } \\
\text { C. klaas }\end{array}$ & 12 & $16-21$ & 2.55 & $41-54$ & $39(25)$ \\
C. cupreus & 12 & $20 ?$ & 1.65 & 33 & $32(4)$ \\
Clamator jacobinus & 12 & $20 ?$ & 2.15 & 43 & $45(2)$ \\
C. levaillantii & 10 & $19-25$ & 5.10 & $97-128$ & $84(22)$ \\
C. glandarius & $10 ?$ & $22 ?$ & 5.60 & 123 & $127(4)$ \\
Cuculus solitarius & 10 & 23 & 9.85 & 226 & $130(10)$ \\
C. clamosus & $10 ?$ & $20 ?$ & 3.22 & 64 & $69(2)$ \\
\hline
\end{tabular}

\footnotetext{
${ }^{1}$ Data on breeding seasons and estimates of the numbers of eggs are from Payne (1973).

${ }^{2}$ Egg weights are from Schönwetter (1960-66), except for C. cupreus which comes from Vernon (1970).

${ }^{3}$ Body weights are taken from females collected in the field in the present study.
}

species. Clutch size is variable (1-2 to 5-6) within each parasitic species sampled well (Fig. 1), perhaps more variable than in nesting cuckoos. In some nesting cuckoos with small clutches the number varies no more than one egg, though in others clutch size varies considerably (Ali and Ripley, 1967; Appert, 1970; Bent, 1940; Ohmart, 1973). Statistical comparisons of variance between nesting and parasitic cuckoos are not possible because of the scarcity of published data on individual clutch sizes of the nesting cuckoos.

Mean clutch size for eight parasitic cuckoo species averaged 3.48 (Fig. 1). Mean clutch sizes for 39 nesting species of cuckoos averaged 2.82 in the five cuckoo subfamilies that rear their own young. The slightly higher average for the parasitic cuckoos is statistically significant (1-tailed $p=.0495$, Mann-Whitney U-test). The value for clutch size of the parasites may be an underestimate as some clutches in the data may have been incomplete, and the value for the nesters may be slightly high because of possible multiple clutches in the Crotophaginae. This group of cuckoos is known to sometimes have nests where more than one female lays. I have included in the data only isolated nests where careful observation indicated only one laying female or where the eggs laid by different females could be differentiated (the eggs of each female being a clutch) in the Crotoph- aga species (Davis, 1940a; Skutch, 1959; Wetmore, 1968; Strauch, unpublished observations), and I have excluded the reported large clutches (all data) for Guira guira which is known to nest communally (Davis, 1940b). Opisthocomus hoatzin is now regarded as a crotophagine and it lays small clutches (Beebe, 1909; Sibley and Ahlquist, 1973). The larger clutch size in the parasitic cuckoos is a difference not apparently paralleled by the parasitic Icteridae, which lay about the same number of eggs in a series as nesting relatives in the same area (Payne, 1965). What the adaptive significance of laying in "clutches," or distinct series, may be in the parasitic cuckoos and the icterids is unknown; the "clutches" of the parasitic cuckoos are less distinctly set off in time than in most other birds.

\section{RePRoductive Rates}

Numbers of eggs laid in a season by African parasitic cuckoos are summarized in Table 1. Most parasitic cuckoos in southern Africa lay 16 to 26 eggs, estimated from the timing of clutches and the length of the breeding season. In southern Africa where most of the samples were taken the breeding season is 10 to 12 weeks (Payne, 1973), and though some tropical cuckoos may have longer breeding seasons, no quantitative accounts of breeding seasons of individual birds are available in local popu- 
lations within $10^{\circ}$ of the equator. In temperate Europe the parasitic cuckoo Cuculus canorus sometimes lays as many as 19 eggs in a five-week season (Chance, 1940; Payne, 1973), and captive Clamator glandarius in Germany (von Frisch, 1969) laid at the same rate as estimated in the field in South Africa.

The numbers of eggs laid in a season by nesting cuckoos are less well known. In North America the breeding seasons of nesting cuckoos may be too short to permit frequent rearing of more than one or two broods (Bent, 1940). However, cuckoos may lay replacement clutches if their first nesting attempts fail. Coccyzus americanus and $C$. erythropthalmus lay from May through September in Oklahoma and Michigan, respectively, and Geococcyx californianus has two breeding seasons in a year in Arizona (Ohmart, 1973), so some females may well rear two broods in a year. In the tropics the breeding seasons of nesting cuckoos are about the same as for parasitic cuckoos (Ali and Ripley, 1969; Mackworth-Praed and Grant, 1953, 1970; Benson et al., 1971; McLachlan and Liversidge, 1970). Probably some tropical nesting cuckoos regularly lay more than two clutches in a season. Some other tropical nesting cuckoos raise no more than one brood in a year (Fogden, 1972). Nesting cuckoos differ from the parasites more in frequency of laying clutches than in clutch size. In general the nesters appear to lay fewer eggs in a season than the parasites, as in the Icteridae (Payne, 1965).

Female parasitic cuckoos appear generally to breed in their first year, and in the species with data available (Clamator glandarius, Cuculus solitarius, and Chrysococcyx caprius) there is no difference in mean clutch size or in number of eggs laid between first-year and older females (Payne, 1973).

\section{Parental Care and the Cost of REPRODUCTION}

The prediction that parasitic birds lay larger clutches and more eggs in a season than their nesting relatives was generated from Lack's principle before any data on the African species were available. The results of the cuckoo study were not anticipated by the argument that "one finds no evidence whatever that parental care and fecundity are in any way dependent" (Williams, 1966a:165). In the fish that Williams discussed, parental care was paternal. But where a female provides much maternal care after she lays her eggs, as in most birds, the apportionment of her energy before and after laying is subject to selection, because maximizing her energy on forming eggs may affect her subsequent reserves for successful parental care, and one would expect females with much parental care to lay proportionally fewer eggs than females with less care.

The early formulation of Lack's (1954) selective principle assumed a balanced polymorphism of genotypes affecting clutch size, with the females laying large clutches favored in good years, and females laying small clutches leaving more young in years of inclement weather. The field work on feeding rates and survival of young in relation to brood size that was encouraged by Lack's principle have resulted in necessary revision of the theory. Whereas differences in clutch size were earlier thought to be due to genetic differences among females, much variance in clutch size is independent of genetic differences (for example, age differences, seasonal differences in clutch size of individuals, responses to ambient environmental food supply and weather) (Lack, 1958; Kluyver, 1963; Klomp, 1970; Perrins, 1971). Nongenetic variability of clutch size is caused by selection for physiological responsiveness to variable environments. Additionally, the amount of food required by young birds in the nest is not necessarily proportional to brood size, as energy consumption may be lower per young in large broods because each young is warmed by its nestmates (Royama, 1966); overheating may result (Mertens, 1969; Royama, 1969). Third, the addition of extra young in the broods of some altricial 
birds causes decreased fledging success, but other species can rear large broods apparently just as well as they can smaller broods (Lack, 1968; Perrins, 1965; Morel, 1967; Hussell, 1972).

A more general criticism of the original parental care principle is that natural selection affects both mortality and natality schedules (Williams, 1966b), not simply the number of young produced at any one time. Hence, the feeding experiments in which adults are unable to rear oversized broods do not necessarily show that clutch size has evolved through selection to maximize brood size in relation to food supply, because the reduced success of large broods may instead be accounted for by adaptive modification of adult behavior. The food/ parental care principle ignores the possible effect of breeding upon the reproductive value of the parent. If adults attempt to rear too large a brood in one year, the stunted young may survive and breed less well themselves than the young from smaller broods (Klomp, 1970), and the parents may have their own future breeding attempts compromised and so lessen their genetic contribution to future generations (Williams, 1966b). Some field evidence indicates that rearing a brood affects the parents' futures. Body weights and fat or protein reserves of both males and females in some passerines decrease while they rear young (Payne, 1969; Ward, 1969; Fogden, 1972; Morton and Welton, 1973). Hussell (1972) found weights of female buntings rearing large broods to be less than those rearing small broods and suggested that parents of large broods may survive and breed less well in later years. Kluyver (1963) found fewer birds with second clutches among the individuals that had reared a large first brood. Experimental reduction of broods of tits increased annual survival rate of the adults (Kluyver, 1971). Some birds decrease in body weight, territory size, and breeding success with age (Balmer and Perrins, 1973), and perhaps these are effects of their individual breeding histories. These data all indicate that rearing a large brood may decrease the reproductive value of the adults, particularly of females.

An individual producing many young early in life may have a lower reproductive value (the likelihood that an individual at a given age will produce offspring in future years and that its offspring will contribute to future generations; Fisher, 1958; Williams, 1966b). Nevertheless, it is unlikely that natality schedules of all animals maximize future reproductive values because an animal that waits and maintains its potential value will be barren while another may breed in the meanwhile and leave offspring, and competition among the offspring of different parents may affect the net reproductive performances of the parents long before their own future reproduction. Selection thus should act directly on the reproductive rates of individuals, not simply upon lifetime performance.

The notion of reproductive value may be of use in predicting some characteristics of reproduction in parasitic birds. Parasites would be expected to lay more eggs than their nonparasitic relatives, because the parasites do not rear their own young and thus should have more energy available to form eggs without compromising their reproductive value. Delayed reproductive maturity in nesters may ultimately be caused by exhaustion of inexperienced breeders (Ashmole, 1963); and as parasites do not rear young, they may be expected to breed in their first year. The following discussion indicates the usefulness of these general ideas as applied to a specific group, but it also brings out the importance of unique attributes of a group.

Egg size.-A few parasitic cuckoos have long been known to lay small eggs (Makatsch, 1955; Lack, 1968). Comparison of 28 parasites and 43 nesting species (all those with data available) shows that parasitic cuckoos lay smaller eggs than do nesting cuckoos of the same body size (Fig. 2). The selective history of egg size in the parasites for allocation of nutrients resulting in the largest number of eggs and young ap- 


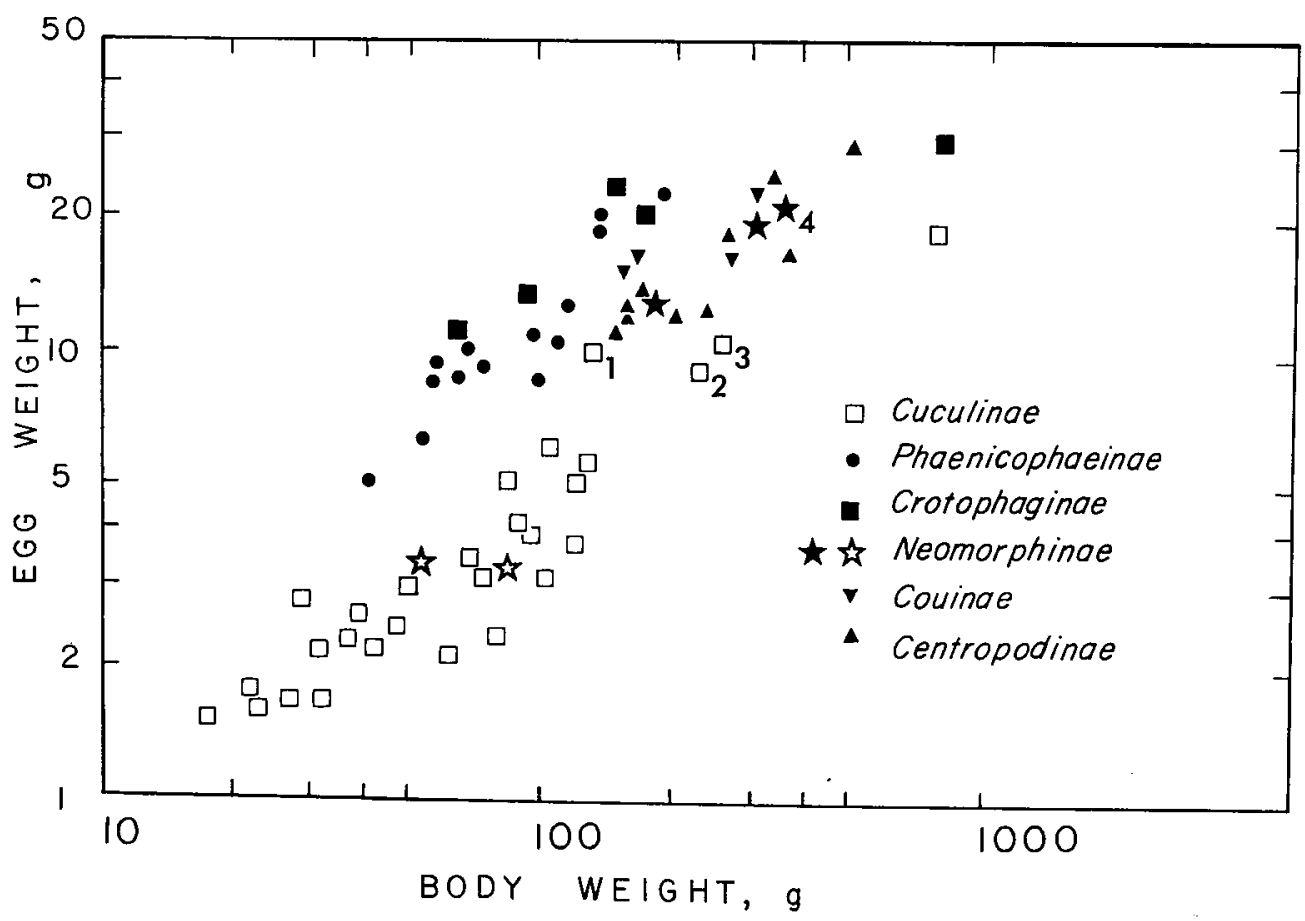

FIG. 2. Relation of egg size to body size in parasitic and nesting cuckoos. Open figures show mean egg weight and mean body weight for parasitic cuckoos, closed figures for nesters. Egg weights are taken mainly from Schönwetter (1960-1966) and are based on egg measurements from collections. Body weights are mainly taken from unpublished specimen weights in museums; some are from numerous articles in regional ornithological journals and museum collection reports. $1=$ Clamator glandarius, $2=$ Eudynamys scolopacea in India, $3=E$. scolopacea in Queensland, $4=$ composite body weights of $N e o-$ morphus geoffroyi and egg of $N$. rufipennis nigrogularis.

pears to involve the evolution of host selection for foster species of small body size by the parasites. A cuckoo can probably leave more young by allocating its resources into forming small eggs rather than to fewer, larger eggs, because small passerine hosts (those much smaller than the cuckoo) are more abundant locally than large passerines (my observations), so parasites using the smaller birds as their hosts have more total nests available to them. Cuckoo eggs are about the same size as the eggs of hosts they parasitize; the size similarity may facilitate heat transfer in incubation and may mollify behavioral reactions of the foster parent to the alien egg. Secondary to the evolution of host selection based on host abundance, there may be a fine-scale adjustment by selection of egg size to mimic host egg size, though no polymorphisms are known for egg size within a local population of cuckoos such as occurs in the color polymorphism of cuckoo eggs, each morph mimicking the color and pattern of a different local host species (Makatsch, 1955; Payne, 1967). Selection for parasitism of small hosts is constrained by some minimal host size as the eggs must be incubated and the young fed. Though the egg is small and the nestling hatches in an unadvanced state, the cuckoo is the sole nestling and it grows rapidly. The foster parents may bring it as much food as they would have to their entire brood.

Deviations from the body size/egg size relationship among the parasitic cuckoos involve species where the young are reared with the host young. The main deviant in 
TABLE 2. Estimates of the caloric costs (kcal) of breeding during a 40-day period in a parasitic cuckoo of $84 \mathrm{~g}$ (Clamator jacobinus) and a hypothetical phaenicophaeine nesting cuckoo of the same body weight.

\begin{tabular}{|c|c|c|c|c|}
\hline \multirow[b]{2}{*}{ Activities } & \multicolumn{2}{|c|}{ Parasitic cuckoo } & \multicolumn{2}{|c|}{ Nesting cuckoo } \\
\hline & Cost/day & Total cost & Cost/day & Total cost \\
\hline \multicolumn{5}{|l|}{ Existence } \\
\hline $\begin{array}{l}\text { SMR } \\
\text { Field existence energy }\end{array}$ & $\begin{array}{c}13.0 \\
?\end{array}$ & 520 & $\begin{array}{c}13.0 \\
?\end{array}$ & 520 \\
\hline \multicolumn{5}{|l|}{ Reproduction } \\
\hline $\begin{array}{l}\text { Egg formation } \\
\text { Incubation ( } 12 \text { days, nester) } \\
\text { Feeding young ( } 22 \text { days, nester) } \\
\text { Other }\end{array}$ & $\begin{array}{c}5.46 \\
0 \\
0\end{array}$ & $\begin{array}{r}164 \\
0 \\
0 \\
?\end{array}$ & $\begin{array}{r}8.26 \\
0 ? \\
13.0\end{array}$ & $\begin{array}{c}49.5 \\
0 ? \\
282 \\
?\end{array}$ \\
\hline Total caloric cost of breeding & & $164+?$ & & $332+?$ \\
\hline
\end{tabular}

Fig. 2 is Clamator glandarius, which parasitizes mainly larger crows, and several young cuckoos per nest may fledge together with the host young (Friedmann, 1964). The eggs and young of these cuckoos are somewhat smaller than those of their crow hosts. The energy of these female cuckoos is better allocated for larger reserves for the embryo allowing increased competitive ability of individual young birds in a crowded nest. Although the crow parasite in India Eudynamys scolopacea also lays several eggs per nest and the young are reared with the host young, it has small eggs, and egg size is not relatively larger in India than in Australian populations of this cuckoo that parasitize smaller hosts (Makatsch, 1955) where the cuckoo may be the only survivor in the brood.

Energy allocation and the cost of breeding.-Even though eggs are small, it costs the female something to produce them, and it would be desirable to determine the differential in reproductive value that follows when a cuckoo lays a different number of eggs, but no data are available. Because one effect of breeding is depletion of an adult's energy reserves and shortened life or depleted reserves for later breeding, it is useful to consider reproductive effort in terms of its time and energetic costs in parasites and in nesting birds.

The time spent in each stage of the nesting cycle has been determined for a few nesting cuckoos. Incubation time ranges from 10 to 14 days in Coccyzus, 14 to 18 in Centropus, 16 in Crotophaga, 17 to 18 in Geococcyx, and 19 in Piaya (Hamilton and Hamilton, 1965; Bent, 1940; Vernon, 1971; Köster, 1971; Ohmart, 1973; Skutch, 1959, $1966 a$ ). The time from hatching to fledging ranges from 7 to 10 days in Crotophaga and Coccyzus (Davis, 1940a; Skutch, 1959; Hamilton and Hamilton, 1965) to 17 to 19 days in Geococcyx (Ohmart, 1973) and a month in Centropus (Ali and Ripley, 1969). Parents may feed their young after fledging for two weeks on the average in the temperate region, longer in anis (Davis, 1940a; Köster, 1971), and at least 10 weeks beyond fledging in some tropical forest cuckoos (Fogden, 1972). The average total time involved from laying to independence of the young may be six weeks; additional time would be involved in nestbuilding and more prolonged parental care.

The energy requirements or cost for breeding in the two groups of cuckoos may be compared in terms of the increase over their standard metabolic rates (SMR), which should be the same for closely related birds regardless of breeding. Table 2 estimates the energy (calculated from the expression for SMR of Lasiewski and Dawson, 1967), in a cuckoo of $84 \mathrm{~g}$, the weight of the parasite Clamator jacobinus. Caloric costs for laying are based on egg size (7.25 $\mathrm{g}$ for $C$. jacobinus, Schönwetter, 1966; 11.0 
$\mathrm{g}$ for a hypothetical nesting cuckoo of $84 \mathrm{~g}$ body weight, estimated from the Phaenicophaeinae in Fig. 2), caloric equivalents of eggs ( $105 \mathrm{kcal}$ for $100 \mathrm{~g}$ wet weight of eggs of small altricial birds, King, 1973), and $70 \%$ efficiency of converting food to eggs (King, 1973). The daily energy expenditure of egg formation would be higher for nesting cuckoos. In a 40-day season the parasite would lay about 15 eggs; parasitic and nesting cuckoos both lay on alternate days, and if the nester lays 3 eggs, the parasite would use three times more energy in making eggs. Development of the embryo in incubation requires heat from the parent and the measured values of metabolic rates of captive birds and heat flow from bird to egg suggest a caloric input equivalent to about $25 \%$ of adult SMR (Drent, 1967). It is uncertain, however, whether the incubating parent must provide heat "in addition to that released as a by-product of the energy metabolism of the nesting parent" (King, 1973), and at least at the warm temperatures of the breeding season incubation may tax only the time and not the energy requirements of nesting birds. Incubation is listed now as costing nothing (Table 2). Costs of rearing young include extra search time for food and if we include the food value given to the young the cost may be a $100 \%$ increase over non-breeding food requirements of the parents (Brisbin, 1969; Dunn, 1973). Additional energetic costs of breeding include nestbuilding and territorial defense, but for these activities no good physiological determinations are available for birds. Breeding female cuckoos of at least some parasitic species do not appear to spend much energy actively searching for host nests, but most often perch and inactively observe the local nestbuilding birds (Chance, 1940; my observations). The strain of breeding on females may be lessened when the male feeds her during the nesting period, as in many nesting cuckoos, and in some parasitic cuckoos also the male feeds the female, who may get most of her food this way (my observations of Chrysococcyx caprius and C. klaas). Considering only egg formation, incubation and feeding the young to two weeks after fledging, the female parasites seem to require no more energy than their nesting relatives do for breeding. Birds in the field would actually operate at a metabolic level higher than in the laboratory where SMR is measured, and maintaining body temperature, searching for food, avoiding predators and so on might increase the energy requirements in the field to as much as the $3.4 \times$ SMR level estimated for passerine birds (King, 1973). The cost of living, apart from breeding, is similar in parasitic and nesting cuckoos of the same body size.

Other aspects of parasitic cuckoos.-Two unique aspects of the biology of parasitic cuckoos should also be considered as they account for much of the laying schedule and are not general features of life histories such as are incorporated into more general theories of selection for breeding rates. Clutch size in parasites may be proximately determined by availability of suitable nests in which to lay. A cuckoo likely could track only a few nesting hosts at any time, the number of nests under observation may correspond with the number of developing ovarian follicles, and the inter-clutch interval may be the time involved for a cue for further ovarian development by finding and watching more nests. Although some cuckoos like Chrysococcyx caprius parasitize colonial hosts (Payne and Payne, 1967), the hosts themselves are often synchronized (Hall, 1970), so the cuckoos may not find suitable nests continuously within a colony, and cuckoos that parasitize colonial hosts do not have larger mean clutches than species parasitizing dispersed hosts. Increased rates of laying in Cuculus canorus have been demonstrated experimentally by increasing the number of available host nests in the field (Chance, 1940). The results of this experiment do not suggest that laying rates are as limited by the amount of food a female can convert into eggs, as much as they are by the number of available nests, because the female was given no extra food 
while it was laying. Perhaps local differences in the number of host nests account for much of the observed variation in cuckoo clutch sizes. Cuckoos may themselves increase the availability of nests by perturbing their nesting hosts causing them to nest again. One laying Clamator jacobinus taken in my study had in its esophagus an eggshell and developed embryo of its host Pycnonotus barbatus. Eating host eggs provides cuckoos with nutrients appropriate for forming eggs themselves, and it also may increase the chance that a host will desert and lay another clutch. If a cuckoo missed laying in one clutch of the host, she may be timed appropriately for the second as she could follow the nesting pair as they renest and find their new nest readily. Though $C$. jacobinus do not, some cuckoos often remove a host egg (Chance, 1940; Makatsch, 1955; Liversidge, 1971). Egg removal by the cuckoos may decrease the likelihood that a host would desert a parasitized clutch because of too many eggs but such an effect appears secondary to the nutritional benefit to the cuckoos and their management of the nesting of their hosts.

Secondly, laying rates are constrained by developmental rates of the cuckoo embryo. Parasitic cuckoos lay on alternate days, and by the time the eggs are laid they have visible embryos. The advanced development of the cuckoo embryos at laying, resulting from a day of internal incubation in the cuckoo oviduct, and the associated short incubation periods enable the parasites' eggs to hatch before the host eggs (Makatsch, 1955; Jensen and Jensen, 1969; Payne, 1973). Newly hatched cuckoos remove the unhatched eggs of the host (Friedmann, 1948; Makatsch, 1955) and with them any competitors for the care of the foster parents, or, in species that do not eject the host eggs, early hatching gives the young a head start in competition for food with the host nestmates. This competitive advantage of advanced development of the young parasite appears to set an ecological limit on laying rates in the cuckoos.

\section{REPRODUCTIVE RATES AND Mortality Rates}

A positive correlation between reproductive rates and mortality rates has been documented for several populations and species, and Emerson (1949), Moreau (1944), Skutch $(1949,1967)$, von Haartman (1971), and others have suggested that reproductive rates generally are selected to compensate for the mortality rates within populations. Lack (1954) however, has explained that natural selection promotes the genotype of individuals leaving the most offspring to the next generation regardless of mortality rates, and he assumed the clutch size was the main way by which birds increased their genetic contributions. The survival of a large brood to fledging or into winter nevertheless is not equivalent to the recruitment of new breeding adults to the population, because the new birds may not be able to establish themselves as breeders. Producing young in numbers sometimes may ensure fewer descendants than would producing fewer young each with a substantial endowment.

Small clutches and small broods may allow some adult birds more time to avoid predators and to compete successfully, thereby increasing their own chances for survival and breeding in a later season (Cody, 1966; Gadgil and Bossert, 1970). Neither predation pressures on adults nor their feeding ecologies appear to differ greatly between the two groups of cuckoos, so this generalization does not seem to predict cuckoo reproductive rates or clutch sizes. Densities of parasitic African cuckoos appear similar to those of North American nesting cuckoos, and both eat many of the same kinds of insect food, especially hairy caterpillars. Annual survival rates are unknown, but museum samples show most parasitic cuckoos to be older than a year (Payne, 1973); Chance (1940) and Blaise (1965) found some females (identified by their eggs) to live for several years. Survival of eggs and nestlings may be low. Niethammer (1938) summarized data from Europe showing that success of Cuculus 
canorus eggs from laying to hatching is $62 \%$ and of young to fledging is $43 \%$. The overall success of $27 \%$ is less than for other European birds reared in open nests (Lack, 1954:75). Clamator jacobinus in coastal South Africa had 20\% fledging success, its local host Pycnonotus capensis had 19\%; both suffered many losses from predators (Liversidge, 1966, 1971). Adult parasitic cuckoos in several species are said to be distasteful to predators, perhaps from noxious chemicals in the caterpillars they eat (Cott, 1946-'47; Cott and Benson, 1971). I have eaten several of these cuckoos raw however and found them palatable, as did vervet monkeys that raided my specimens. Aside from any possible aposematic forms, cuckoos are mostly dull-plumaged and inconspicuous (Payne, 1967); both hosts and predators may overlook them. These observations suggest that predation rates on adult parasitic cuckoos are not grossly higher or lower than those on nesting birds.

Much in the recent discussion of " $r$ " and " $K$ " selection and "strategies" of evolution of reproductive rates has assumed that the selective advantage of birth rates depends directly on mortality rates within a population (Lewontin, 1965; MacArthur and Wilson, 1967; Cody, 1966, 1971). In populations that frequently are under densitydependent restraints on population size we might expect natural selection to favor individuals that can adjust their reproductive effort to prevailing ecological conditions. The abundance of resources available may depend on population density, and as changes in population density are caused in part by mortality changes, it can be reasoned that phenotypic adaptability of reproductive rates are selected. It is more difficult to accept the premise that longterm mortality rates over many generations will provide a demographic environment favoring selection for high or low birth rates independent of the resources available to individuals. When disassociated from the implication of direct cause the $r$ and $K$ selection concepts are useful in compari- sons of the evolutionary ecology among populations and species (Gadgil and Solbrig, 1972; Pianka, 1972), and indirectly these strategic arguments may help explain the evolution of cuckoo life histories, though none of these workers made specific predictions about this group. Reproductive rates may somehow be balanced, in the long run, against mortality rates in the evolution of breeding "strategies." But the balance is not the simple one of high mortality rates directly causing high reproductive rates.

Perhaps none of our general theories of the evolution of reproductive rates are really general if they cannot predict observed life-historical adaptations of organisms unlike those on which the theories were inductively based. Data on real animals such as the parasitic cuckoos do not refute these theories, but indicate their inadequacies with respect to certain life history and behavioral phenomena.

\section{SUMMARY}

Parasitic cuckoos lay larger clutches and they lay many more eggs per year than their non-parasitic relatives. The increase in reproductive rate is accomplished through increasing the number of "clutches" in a season more than the number of eggs in a clutch. In this special case, reproductive effort estimated in terms of caloric costs involves a reallocation of energy normally expended on nestbuilding, incubation, feeding the young, and possibly female territorial behavior, but the total cost of breeding appears to be less in the parasites than in the nesting cuckoos. Specializations of (a) egg size adapted to match the eggs of the more abundant hosts and of (b) advanced embryonic development at laying constrain the number of eggs laid in a season.

The results were compared with several general theories of the evolution of reproductive rates, and they seem to be best explained by models of parental food limitation (Lack, 1954) and the cost/benefit approach of Williams (1966b). Though 
reproductive rates may be adjusted evolutionarily to prevailing mortality rates within populations, adjustment appears to be at best indirect.

\section{ACKNowLEDGMENTS}

Research was supported by the National Science Foundation. Gloria Sullivan helped make the serial sections. For their weight data I thank the Australian Bird-banding Scheme, CSIRO (D. Purchase), Australian Museum (H. J. de S. Disney), Queensland Museum (D. P. Vernon), National Museum of Victoria (A. R. McEvey), Western Australian Museum (G. M. Storr), Dominion Museum, Wellington (D. C. Kinsky), Field Museum of Natural History (M. A. Traylor), Museum of Vertebrate Zoology (N. K. Johnson), Royal Ontario Museum (R. I. Orenstein), National Museum of Zambia (R. J. Dowsett), and National Museum of Rhodesia (M. P. S. Irwin). Martin Cody, Erica Dunn, Nelson Hairston, Henry Howe, Bert Murray, Karen Payne, Paul Sherman, Robert Storer, and Joe Strauch made critical comments on the manuscript.

\section{Literature Cited}

AII, S., AND S. D. RIPLEY. 1969. Handbook of the birds of India and Pakistan. Vol. 3. Oxford Univ. Press, Bombay.

Amadon, D. 1964. The evolution of low reproductive rates. Evolution 18:105-110.

APPERT, O. 1970. Zur Biologie einiger KuaArten Madagaskars (Aves, Cuculi). Zool. Jb. Syst. Bd. 97:424-453.

Asmmole, N. P. 1963. The regulation of numbers of tropical oceanic birds. Ibis $103 \mathrm{~b}: 458-$ 473.

Beebe, C. W. 1909. A contribution to the ecology of the adult hoatzin. Zoologica 1:45-66.

Benson, C. W., R. K. Brooke, R. J. Dowsett, AND M. P. S. IRWIN. 1971. The birds of Zambia. Collins, London.

Bent, A. C. 1940. Life histories of North American cuckoos, goatsuckers, hummingbirds, and their allies. Bull. U.S. Nat. Museum 176.

Blaise, M. 1965. Contribution à l'étude de la reproduction du coucou gris Cuculus canorus dans le nord-est de la France. L'Oiseau et R.F.O. 35:87-116.

BrISBIN, I. L. 1969. Bioenergetics of the breeding cycle of the ring dove. Auk 86:54-74.
Bulmer, M. G., and C. M. Perrins. 1973. Mortality in the great tit (Parus major). Ibis 115: $277-281$.

Chance, E. P. 1940. The truth about the cuckoo. Country Life Ltd., London.

Cony, M. L. 1966. A general theory of clutch size. Evolution 20:174-184.

—. 1971. Ecological aspects of reproduction. In D. S. Farner and J. R. King (eds.), Avian biology, Vol. 1. Academic Press, New York.

Cotт, H. B. 1946-1947. The edibility of birds: illustrated by five years' experiments and observations (1941-1946) on the food preferences of the hornet, cat and man; and considered with special reference to the theories of adaptive colouration. Proc. Zool. Soc. London 116:371-524.

Cott, H. B., and C. W. Benson. 1971. The palatability of birds, mainly based upon observations of a tasting panel in Zambia. Ostrich Suppl. 8:357-384.

Davis, D. E. 1940a. Social nesting habits of the smooth-billed ani. Auk 57:179-218.

—. 1940b. Social nesting habits of Guira guira. Auk 57:472-484.

Drent, R. H. 1967. Functional aspects of incubation in the herring gull (Larus argentatus Pont.). E. J. Brill, Leiden.

Duns, E . H. 1973. Energy allocation of nestling double-crested cormorants. Ph.D. dissertation, University of Michigan.

Emerson, A. E. 1949. Natural selection. In W. C. Allee, A. E. Emerson, O. Park, T. Park, and K. P. Schmidt. Principles of animal ecology. W. B. Saunders, Philadelphia.

FISHER, R. A. 1958. The genetical theory of natural selection. 2nd revised ed. Dover, New York.

Fogden, M. P. L. 1972. The seasonality and population dynamics of equatorial forest birds in Sarawak. Ibis 114:307-343.

FriedmanN, H. 1948. The parasitic cuckoos of Africa. Washington Acad. Sci., Monogr. No. 1.

—. 1964. Evolutionary trends in the avian genus Clamator. Smithsonian Misc. Coll. 146 (4) : 1-127.

Gadgrl, M., and W. H. Bossert. 1970. Life historical consequences of natural selection. Amer. Natur. 104:1-24.

GadgIL, M., ANd O. T. Solbrio. 1972. The concept of $r$ - and $K$-selection: evidence from wild flowers and some theoretical considerations. Amer. Natur. 106:14-31.

HALL, A. R. 1970. Synchrony and social stimulation in colonies of the black-headed weaver Ploceus cucullatus and Vieillot's black weaver Melanopteryx nigerrimus. Ibis 112:93-104.

Hamilton, W. J., and M. E. Hammton. 1965. Breeding characteristics of yellow-billed cuckoos in Arizona. Proc. Calif. Acad. Sci., 4th Ser., $32: 405-432$. 
Hussell, D. J. T. 1972. Factors affecting clutch size in arctic passerines. Ecol. Monogr. 42:317362.

Jensen, R. A. C., AND M. K. Jensen. 1969. On the breeding biology of southern African cuckoos. Ostrich 40:163-181.

KING, J. R. 1973. Energetics of reproduction in birds. In D. S. Farner (ed.), Breeding Biology of birds. National Academy of Sciences, Washington, D. C.

KLOMP, H. 1970. The determination of clutchsize in birds, a review. Ardea 58:1-124.

KLUyver, H. N. 1963. The determination of reproductive rates in paridae. Proc. 13th Int. Orn. Congr. 706-716.

- 1971. Regulation of numbers in populations of great tits (Parus $m$. major). Proc. Adv. Study Inst. Dynamics Numbers Popul. (Oosterbeek, 1970):507-523.

Köster, F. 1971. Zum Nistverhalten des Ani, Crotophaga ani. Bonn. Zool. Beitr. 22:4-27.

LACK, D. 1954. The natural regulation of animal numbers. Clarendon Press, Oxford.

- - 1958. A quantitative breeding study of British tits. Ardea 46:91-124.

—. 1968. Ecological adaptations for breeding in birds. Methuen, London.

LasIewski, R. C., AND W. R. Dawson. 1967. A re-examination of the relation between standard metabolic rate and body weight in birds. Condor 69:13-23.

Lewontin, R. C. 1965. Selection for colonizing ability. In H. G. Baker and G. L. Stebbins (eds.), The genetics of colonizing species. Academic Press, New York.

Lrversidge, R. 1966. Fluctuations in a breeding population in the eastern Cape. Ostrich Suppl. $6: 419-424$.

- 1971. The biology of the jacobin cuckoo Clamator jacobinus. Ostrich Suppl. 8:117-137.

MacArthur, R. H., AND E. O. Wilson. 1967. The theory of island biogeography. Princeton Univ. Press, Princeton.

Mackworth-Praed, C. W. and C. H. B. Grant. 1957. Birds of Eastern and North Eastern Africa. Vol. 1, Ed. 2. Longmans, Green and Co., London.

- 1970. Birds of West Central and Western Africa. Vol. 1, Longmans, Green and Co., London.

Makatsch, W. 1955. Der Brutparasitismus in der Vogelwelt. Neumann Verlag, Radebeul.

Mclachtan, G. R., and R. Liversidge. 1970. Roberts birds of South Africa. Bird Book Fund, Cape Town.

Mertens, J. A. L. 1969. The influence of brood size on the energy metabolism and the water loss of nestling great tits Parus major major. Ibis $111: 11-16$.
Moreau, R. E. 1944. Clutch-size: a comparative study, with special reference to African birds. Ibis $86: 286-347$.

Morel, M. Y. 1967. Les oiseaux tropicaux élèvent-ils autant de jeunes qu'ils peuvent en nourrir? le cas de Lagonosticta senegala. Terre Vie 1967:77-82.

Morton, M. L., ANd D. E. Welton, 1973. Postnuptial molt and its relation to reproductive cycle and body weight in mountain whitecrowned sparrows (Zonotrichia leucophrys oriantha). Condor 75:184-189.

Niethammer, G, 1938. Handbuch der Deutschen Vögelkunde. Band II. Akademische Verlagsgesellschaft, Leipzig.

OHMaRT, R. D. 1973. Observations on the breeding adaptations of the roadrunner. Condor 75 : 140-149.

Payne, R. B. 1965. Clutch size and numbers of eggs laid by brown-headed cowbirds. Condor 67:44-60.

—. 1966. The post-ovulatory follicles of blackbirds. J. Morph. 118:331-352.

- 1967. Interspecific communication signals in parasitic birds. Amer. Natur. 101:363-376.

1969. Breeding seasons and reproductive physiology of tricolored blackbirds and redwinged blackbirds. Univ. Calif. Publ. Zool. 90.

- 1973. Individual laying histories and the clutch size and numbers of eggs of parasitic cuckoos. Condor 75:414-438.

Payne, R. B., AND K. Payne. 1967. Cuckoo hosts in southern Africa. Ostrich 38:135-143.

Perrins, C. M. 1965. Population fluctuations and clutch-size in the great tit, Parus major L. J. Anim. Ecol. 34:601-647.

- 1971. Population studies of the great tit, Parus major. Proc. Adv. Study Inst. Dynamics Numbers Popul. (Oosterbeek, 1970):524-531.

PIANKA, E. R. 1972. $r$ and $K$ selection or $b$ and $d$ selection? Amer. Natur. 106:581-588.

Royama, T. 1966. Factors governing feeding rate, food requirement and brood size of nestling great tits Parus major. Ibis 108:313-347.

-.. 1969. A model for the global variation of clutch size in birds. Oikos 20:562-567.

ScHönwerter, M. 1960-66. Handbuch der Öologie. Akademie-Verlag, Berlin.

Sibley, C. G., AND J. E. Ahlquist. 1973. The relationships of the hoatzin. Auk 90:1-13.

Skutch, A. F. 1949. Do tropical birds rear as many young as they can nourish? Ibis 91: $430-455$.

- 1959. Life history of the groove-billed ani. Auk 76:281-317.

- 1966. Life history notes on three tropical American cuckoos. Wilson Bull. 78:139-165.

- 1967. Adaptive limitation of the reproductive rate of birds. Ibis 109:579-599. 
SNow, D. 1962. A field study of the black and white manakin, Manacus manacus, in Trinidad, W. I. Zoologica 47:199-221.

Vernon, C. J. 1970. New host species for three cuckoos. Ostrich 41:258.

voN FrISCH, O. 1969. Die Entwicklung des Häherkuckucks (Clamator glandarius) im Nest der Wirtsvogel und seine Nachzucht in Gefangenschaft. Z. Tierpsychol. 26:641-650.

von HaArtman, L. 1971. Population dynamics. In D. S. Farner and J. R. King (eds.), Avian biology, vol. 1. Academic Press, New York.
WARD, P. 1969. The annual cycle of the yellowvented bulbul Pycnonotus goiavier in a humid equatorial environment. J. Zool. (London) 157:25-45.

Wetmore, A. 1968. The birds of the Republic of Panama. Part 2. Smithsonian Misc. Coll. 150.

Winltams, G. C. 1966a. Adaptation and natural selection. Princeton Univ. Press, Princeton.

—. 1966b. Natural selection, the costs of reproduction, and a refinement of Lack's principle. Amer. Natur. 100:687-692. 